\title{
Electrophysiological stimulation (Tsui test) is feasible for epidural catheter positioning in adults with chronic back pain: a cohort study
}

\section{La stimulation électrophysiologique (test de Tsui) est faisable pour le positionnement d'un cathéter péridural chez l'adulte souffrant de maux de dos chroniques: une étude de cohorte}

\author{
Niamh A. McAuliffe, MBBCh • Sharon Pickworth, MBBS · \\ Tania DiRenna, MD $\cdot$ Aaron Hong, MD \\ Received: 13 March 2013/Accepted: 11 July 2013/Published online: 3 August 2013 \\ (C) Canadian Anesthesiologists' Society 2013
}

\begin{abstract}
Purpose Determining epidural catheter placement and accurately depositing corticosteroids at the site of the pathology in adults with chronic back pain can be challenging. Fluoroscopy is considered the standard of care for guiding epidural catheter positioning and subsequent injection in patients receiving epidural corticosteroids, but the technique has some limitations. We hypothesized that electrophysiological stimulation using the Tsui test is feasible for determining the appropriate epidural catheter position in adults with chronic back pain receiving epidural corticosteroids.

Methods We conducted a prospective cohort study of 12 patients receiving epidural corticosteroid injections for chronic back pain. Anatomical landmarks and epidural needle positions were initially confirmed by fuoroscopy. Epidural catheter position was assessed according to
\end{abstract}

\begin{abstract}
Author contributions Niamh McAuliffe made substantial contributions to conception and design, acquisition of data, analysis and interpretation of data; drafted the article and revised the manuscript; and approved the final version to be published. Sharon Pickworth made substantial contributions to conception and design, acquisition of data; revised the manuscript; and approved the final version to be published. Tania DiRenna made substantial contributions to conception and design, acquisition of data; and revised the manuscript; and approved the final version to be published. Aaron Hong made substantial contributions to conception, design, acquisition of data, analysis and interpretation of data; revised the manuscript; and approved the final version to be published.
\end{abstract}

N. A. McAuliffe, MBBCh $(\square) \cdot$ S. Pickworth, MBBS

T. DiRenna, MD $\cdot$ A. Hong, MD

Department of Anesthesia and Pain Medicine, St. Michael's

Hospital, 30 Bond St, Toronto, ON M5B 1W8, Canada

e-mail: mcauliffeniamh@gmail.com sensory and motor responses, as described by Tsui et al. (Can J Anaesth 45: 640-644, 1998). The current was increased slowly from zero until muscle activity was visible or the current reached $10 \mathrm{~mA}$. The catheter was then advanced until muscle responses occurred in the desired myotome. The test was deemed positive or negative according to the Tsui criteria. The anatomical level was confirmed by fluoroscopy prior to injection.

Results Electrophysiological stimulation effectively established the appropriate epidural catheter position in 11 patients (92\%). Epidural stimulation occurred at a mean (SD) threshold of 3.95 (3.35) $\mathrm{mA}$. The kappa statistic between interventions was 0.65 , indicating a substantial level of agreement.

Conclusion This study demonstrated that electrophysiological stimulation using the Tsui technique is feasible for epidural catheter positioning in adults with chronic back pain. It may optimize epidural steroid injection in this population.

\section{Résumé}

Objectif Il peut être difficile de déterminer le positionnement du cathéter péridural et de placer de façon précise les corticostéroïdes au site de la lésion chez les adultes souffrant de maux de dos chroniques. La fluoroscopie est considérée comme la norme de soins pour guider le positionnement $d u$ cathéter péridural et l'injection subséquente chez les patients recevant des corticostéroüdes par voie péridurale, mais la technique comporte certaines limites. Nous avons émis l'hypothèse que la stimulation électrophysiologique réalisée à l'aide du test de Tsui était faisable pour déterminer le positionnement adéquat du cathéter péridural chez les adultes souffrant de maux de dos 
chroniques et recevant des corticostéroüdes par voie péridurale.

Méthode Nous avons réalisé une étude de cohorte prospective auprès de 12 patients recevant des injections péridurales de corticostéroüdes pour le traitement de maux de dos chroniques. Les repères anatomiques et les positions des aiguilles péridurales ont d'abord été confirmés par fluoroscopie. Le positionnement du cathéter péridural a été évalué selon les réponses sensitives et motrices suivant l'application de courant électrique, lequel a été lentement augmenté de zéro jusqu'à observation d'une activité musculaire ou jusqu'à atteindre $10 \mathrm{~mA}$. Le cathéter a ensuite été avancé jusqu'à la survenue de réponses musculaires dans le myotome souhaité. Le test a été jugé positif ou négatif selon les critères de Tsui. Le niveau anatomique a été confirmé par fluoroscopie avant l'injection. Résultats La stimulation électrophysiologique a permis d'établir de façon efficace le positionnement adéquat du cathéter péridural chez 11 patients (92\%). La stimulation péridurale est survenue à un seuil moyen (ÉT) de 3,95 $(3,35) m A$. L'indice kappa entre les interventions était de 0,65 , ce qui indique un important degré de concordance.

Conclusion Cette étude a démontré que la stimulation électrophysiologique à l'aide de la technique de Tsui est faisable pour le positionnement du cathéter péridural chez l'adulte souffrant de maux de dos chroniques. Cette méthode pourrait optimiser l'injection péridurale de corticostéroïdes chez cette population.

Chronic low back pain is routinely managed with epidural corticosteroids. $^{1,2}$ To ensure an optimal response to this intervention, the injectate must be deposited within the epidural space in close proximity to the site of the pathology. ${ }^{3}$ The approaches commonly used to inject corticosteroid are 1) directly through an epidural needle or 2) via a catheter threaded into the epidural space. ${ }^{4}$ For both techniques, fluoroscopy is the standard of care to confirm that the epidural needle or catheter tip is properly positioned prior to injection. ${ }^{5-7}$ However, suboptimal corticosteroid placement is relatively common (23-53\%) using fluoroscopy for confirmation, which can affect pain outcomes and patients' satisfaction. ${ }^{8,9}$

With this problem in mind, Tsui et al. described an objective, reliable technique for confirming appropriate epidural catheter placement using electrophysiological stimulation. These investigators applied low-current electrical stimulation to nerves via an epidural catheter and assessed the patient's sensory and motor responses. ${ }^{10-12}$ The Tsui test is considered positive (proper epidural catheter positioning) if there is a myotome response, either unilateral or bilateral, with a current of $1-10 \mathrm{~mA}$ and if the magnitude of the response is independent of the placement of the ground electrode. ${ }^{10}$ The Tsui test is negative if a current of less than $1 \mathrm{~mA}$ elicits a motor response, which would imply either subarachnoid placement or placement against a nerve root. Motor responses of more than $10 \mathrm{~mA}$ suggest catheter placement outside the epidural space. The myotome level of the response to electrophysiological stimulation has been shown to correspond to the spinal column level of the epidural catheter's position. ${ }^{13}$

To date, the Tsui test has not been described for epidural catheter positioning in patients with chronic back pain. The intervention, however, has the potential to benefit individuals with pain whose symptoms do not correlate with the radiologically identified lesion. We hypothesized that it is feasible to apply electrophysiological stimulation with the Tsui test to determine the appropriate position for the epidural catheter tip in adults with chronic back pain receiving epidural corticosteroids. The primary outcome of our study was to establish the feasibility of using the Tsui test for epidural catheter placement in this population. A secondary outcome was to compare the optimal epidural catheter position using the Tsui test with the expected anatomical level using fluoroscopy.

\section{Methods}

With Research Ethics Board approval from St Michael's Hospital (May 2010), all patients aged $>18 \mathrm{yr}$ with chronic back pain undergoing elective epidural injection of corticosteroids were assessed for eligibility from May 2010 to January 2011. An anesthesiologist independent of the research and interventional teams obtained informed written consent from the patients. Chronic back pain was defined as back pain of more than three months' duration that was not directly related to neoplastic involvement but was associated with a chronic medical condition or extending in duration beyond the expected temporal boundary of tissue injury and normal healing, and adversely affecting the function or well-being of the individual. ${ }^{14}$ The decision to proceed with epidural steroid injection was based on radiological imaging and the location and severity of the pain. Exclusion criteria included non-English-speaking persons, women of childbearing age, patients with implanted electronic devices, patient refusal, any contraindications to neuraxial intervention, and/or allergy to radiopaque contrast, corticosteroids, or local anesthetics.

After establishing standard monitoring and intravenous access, each patient was positioned prone. Anatomical landmarks were confirmed by fluoroscopy. The skin over the sacral hiatus was prepared using a sterile technique, and $5 \mathrm{~mL}$ of $1 \%$ lidocaine was infiltrated into the skin and 
subcutaneous tissues overlying the sacral hiatus. A $17 \mathrm{G}$ Tuohy needle was inserted using a "loss of resistance to air" technique. The needle position was confirmed using fluoroscopy. A 19G catheter (Arrow Flex Tip Plus: Arrow International, Reading, PA, USA) was connected to a nerve stimulator via an adaptor (Johans ECG Adaptor; Arrow International). ${ }^{15,16}$ The catheter was filled with normal saline and advanced into the epidural space.

The epidural stimulation test was performed as described by Tsui et al. ${ }^{17}$ The anode lead of the nerve stimulator was connected to an electrode on the patient's upper extremity. The nerve stimulator was set at a frequency of $1 \mathrm{~Hz}$ and a pulse width of $0.2 \mathrm{msec}$. The current was increased slowly from zero until lower limb muscle activity was visible or until the current reached a maximum of $10 \mathrm{~mA}$. The catheter was advanced until muscle responses occurred in the desired myotome. The patient was questioned regarding pain at the targeted myotome level. A second observer documented motor responses. The test was deemed positive or negative according to the Tsui criteria. ${ }^{10}$ Positive criteria required that the current was within the range of 1-10 $\mathrm{mA}$, the motor response could be unilateral or bilateral, and the motor response should be unchanged in terms of strength or location regardless of placement of the anode ground electrode. The catheter was deemed to be outside the epidural space if the patient did not respond, or the strength and location of the motor response changed with anode repositioning. The test was also deemed negative if the current required was less than $1 \mathrm{~mA}$ (indicating subarachnoid placement). ${ }^{10,18}$ The catheter was aspirated to rule out intrathecal or intravascular placement before the final position was confirmed. The duration of the procedure was defined as the time from first needle insertion to final confirmation of the position. The threshold current required to elicit a motor response at the final catheter position was recorded. More than three attempts at positioning using electrophysiological stimulation was considered a failure, and the Tsui test was stopped.

After a negative aspiration, $3 \mathrm{~mL}$ of contrast material (Omnipaque 240, GE Healthcare Inc., Princeton, NJ, USA) was injected. Distribution of the contrast medium was visualized using fluoroscopy. The catheter tip position was identified using anteroposterior and lateral radiological images. The anatomical position of the catheter tip was documented to the nearest upper vertebral level. A treatment solution of methylprednisolone $40 \mathrm{mg}$ and $0.2 \%$ lidocaine $10 \mathrm{~mL}$ was injected incrementally through the epidural catheter.

The purpose of this study was to determine the feasibility of using electrophysiological stimulation with the Tsui test to guide epidural catheter positioning in adults with chronic back pain. Consequently, no formal sample size was calculated, but using data from other feasibility studies with the Tsui test to attain a sample size of 12 was deemed appropriate. ${ }^{11,12}$ Data are reported as means and standard deviations or as medians and interquartile ranges as appropriate. The kappa statistic was used to test for agreement between the interventions. It was interpreted as: $\kappa<0$, poor agreement; $0-0.2$, slight; 0.21 0.40, fair; 0.41-0.60, moderate; 0.61-0.80, substantial; 0.811.0 , almost perfect.

\section{Results}

The demographic data of all participants are summarized in Table 1 . The procedure was well tolerated by all patients, and no adverse effects were reported within six months of the intervention. The mean (standard deviation $[\mathrm{SD}]$ ) time to perform each procedure was 21.6 (7.8) min. Epidural stimulation occurred at a mean (SD) threshold of 3.95 (3.35) $\mathrm{mA}$. The median (interquartile range) number of attempts for repositioning were 2 (1-3). Ten catheters $(83 \%)$ produced a unilateral response (Table 2 ). For one patient (Table 2; patient five) it was not possible to establish epidural placement using the Tsui test alone. The epidural position was subsequently confirmed using fluoroscopy, resulting in a success rate of $92 \%$. The level of agreement between fluoroscopy and the Tsui test was substantial for the 11 successful participants. The kappa statistic (95\% confidence interval) between techniques was 0.65 (0.26 to 1.04$)$.

\section{Discussion}

This study investigated the feasibility of using electrophysiological stimulation with the Tsui technique for positioning the epidural catheter in adults with chronic

Table 1 Demographic data

\begin{tabular}{llll}
\hline Patient no. & Sex (male/female) & Age (yr) & $\begin{array}{l}\text { ASA physical status } \\
\text { classification }\end{array}$ \\
\hline 1 & F & 53 & II \\
2 & F & 48 & III \\
3 & F & 69 & II \\
4 & F & 47 & II \\
5 & M & 83 & III \\
6 & M & 54 & II \\
7 & F & 73 & II \\
8 & F & 52 & I \\
9 & F & 83 & III \\
10 & F & 77 & III \\
11 & M & 57 & I \\
12 & M & 65 & II \\
\hline ASA & Am & &
\end{tabular}

ASA $=$ American Society of Anesthesiologists 
Table 2 Summary of electrophysiological responses

\begin{tabular}{|c|c|c|c|c|c|c|}
\hline $\begin{array}{l}\text { Table } 2 \text { Summary of } \\
\text { electrophysiological responses }\end{array}$ & $\begin{array}{l}\text { Patient } \\
\text { no. }\end{array}$ & $\begin{array}{l}\text { Attempts } \\
\text { (n) }\end{array}$ & $\begin{array}{l}\text { Electrical } \\
\text { threshold } \\
(\mathrm{mAmp})\end{array}$ & $\begin{array}{l}\text { Sensory or motor } \\
\text { level elicited } \\
\text { by Tsui test }\end{array}$ & $\begin{array}{l}\text { Anatomical } \\
\text { position of } \\
\text { catheter tip }\end{array}$ & Response \\
\hline & 1 & 3 & 6.0 & L4-5 & L4-5 & Sensory and motor \\
\hline & 2 & 3 & 1.9 & L5-S1 & L4-5 & Sensory \\
\hline & 3 & 2 & 1.5 & L5-S1 & L5-S1 & Motor \\
\hline & 4 & 2 & 3.0 & L5-S1 & L5-S1 & Motor \\
\hline & 5 & 3 & $\mathrm{n} / \mathrm{a}$ & $\mathrm{n} / \mathrm{a}$ & L5-S1 & No sensory or motor \\
\hline & 6 & 2 & 6.0 & L4-5 & L3-4 & Motor \\
\hline & 7 & 1 & 1.5 & L4-5 & L4-5 & Sensory and motor \\
\hline & 8 & 1 & 10 & L5-S1 & L5-S1 & Motor \\
\hline & 9 & 3 & 4.0 & L4-5 & L4-5 & Sensory and motor \\
\hline & 10 & 2 & 2.0 & L5-S1 & L5-S1 & Motor \\
\hline & 11 & 2 & 10 & L5-S1 & L5-S1 & Sensory \\
\hline & 12 & 1 & 1.5 & L5-S1 & L5-S1 & Sensory \\
\hline
\end{tabular}

$\mathrm{n} / \mathrm{a}=$ not available

back pain who were receiving epidural corticosteroids. We showed a substantial level of agreement between electrophysiological stimulation using the Tsui technique and those using fluoroscopy in this population. The studied technique may have the potential to optimize the deposition of corticosteroids at the site of the pathology and consequently improve outcomes in this population.

Current guidelines recommend that interventionalists performing epidural injections aim to deposit corticosteroids in the ventral part of the epidural space, near the targeted nerve root. ${ }^{19}$ Epidural injections at the level of the lumbar spine are performed via caudal, transforaminal, and interlaminar routes. Caudal epidural injections are frequently performed using fluoroscopy guidance as it is considered the safest technique for this purpose, with minimal risk of dural puncture. ${ }^{4} \mathrm{We}$ found, however, that the Tsui test may be used to deposit the corticosteroid dose more accurately at the site of pathology while retaining a safety profile similar to that seen with the traditional fluoroscopy-guided caudal approach to the epidural space.

The position of the epidural catheter tip has significant implications regarding clinical outcomes following epidural corticosteroid injections, and fluoroscopy has been widely cited as the standard of care for determining its position. ${ }^{20,21}$ Clinical outcomes are improved when the corticosteroid is deposited in close proximity to the site of pathology. ${ }^{9}$ Malpositioning can lead to intrathecal or intravascular injection of the corticosteroid, resulting in significant morbidity. ${ }^{22}$

The disadvantages of fluoroscopy include ongoing radiation exposure for the patient and the risk of an allergic reaction to the radiopaque contrast material following repeated exposure. ${ }^{23,24}$ Use of fluoroscopy also adds significantly to the overall cost of the procedure. ${ }^{25}$
Hogan et al. highlighted the inadequacies of radiological imaging to identify the proper position of the subdural catheter tip when performing epidural injections. ${ }^{26}$ These positions can vary significantly, with the catheter frequently positioned lateral to the dura in the intervertebral foramen. ${ }^{27}$ A recent American Society of Anesthesiologists Task Force on Chronic Pain Management found that there was still insufficient evidence to determine the clinical impact of image guidance when choosing the site of an epidural injection. ${ }^{14}$

Although fluoroscopy is still considered the standard of care for epidural catheter placement, alternative or complementary techniques could provide considerable benefit for patients who require deposition of epidural corticosteroids. The reliability of electrophysiological testing for epidural catheter placement has been confirmed in studies of obstetrical and pediatric patients. $^{28,29}$ The technique has the advantage of offering physiological confirmation of the myotome level of the epidural catheter tip by demonstrating an appropriate motor response. Tsui et al. had a high success rate using electrical stimulation to guide catheter placement to the desired position in the epidural space. ${ }^{12}$ Their technique has also been used successfully to guide placement of thoracic epidural catheters via the caudal route in small infants and children. $^{28,30}$

In our study, the Tsui test elicited isolated sensory responses in only three patients (3/12), with no motor responses. Two of the patients required threshold currents of $10 \mathrm{~mA}$ to elicit a response. Originally, Tsui et al. suggested a motor response threshold of $10 \mathrm{~mA}$ as the cutoff value to distinguish between epidural and nonepidural catheter locations. However, Tsui et al. recently confirmed that currents of more than $10 \mathrm{~mA}$ are required in some cases and may even reach upward of 
$17 \mathrm{~mA} .{ }^{11}$ There appears to be no current consensus as to the appropriate upper limit for the current, but there is agreement that the distribution of the motor response is more important than the actual current required. ${ }^{28}$ Tsui et al. previously reported mean thresholds of 3.78 and $4.9 \mathrm{~mA} .{ }^{11}$ The time required to perform the procedure in our study was $21.6 \mathrm{~min}$, which is comparable to the time needed to perform blind caudal corticosteroid injections (range $8-21 \mathrm{~min}){ }^{31}$

The notable limitation of our study is the small sample size. The project was designed as a feasibility study to aid future investigations regarding the effectiveness of this intervention. It had a sample size comparable to those of other feasibility studies using the Tsui test. ${ }^{11,12}$ Although the study was not powered to make comparisons between interventions, we found a substantial, but not statistically significant, correlation between the Tsui test and fluoroscopy for determining the appropriate position for the epidural catheter tip. We also used a compliant epidural catheter, which may have affected the accuracy of the positioning and consequently the procedure time. A directable catheter (such as those used for epidural neuroplasty) might have allowed greater speed and more maneuverability within the epidural space. ${ }^{32}$

This study demonstrated that electrophysiological stimulation using the Tsui technique is feasible for positioning epidural catheters in adults with chronic back pain who require epidural corticosteroids. The procedure was well tolerated by all patients. Also, the patients were able to contribute to optimal positioning of the epidural catheter by providing feedback about sensory and motor symptoms during the procedure. This intervention has the potential to benefit individuals with pain whose symptoms do not correlate with the radiologically diagnosed lesion. There was a good correlation between electrophysiological stimulation using the Tsui technique and fluoroscopy in this population in regard to positioning the catheter tip. Further studies are required to determine whether this approach can improve patient outcomes.

\section{Sources of funding None. \\ Conflict of interest None declared.}

\section{References}

1. Abdi S, Datta $S$, Lucas $L F$. Role of epidural steroids in the management of chronic spinal pain: a systematic review of effectiveness and complications. Pain Physician 2005; 8: 127-43.

2. Boswell MV, Trescot AM, Datta S, et al. Interventional techniques: evidence-based practice guidelines in the management of chronic spinal pain. Pain Physician 2007; 10: 7-111.
3. Manchikanti L, Singh V, Cash KA, Pampati V, Damron $K S$, Boswell $M V$. A randomized, controlled, double-blind trial of fluoroscopic caudal epidural injections in the treatment of lumbar disc herniation and radiculitis. Spine (Phila Pa 1976) 2011; 36: 1897-905.

4. Abdi S, Datta S, Trescot AM, et al. Epidural steroids in the management of chronic spinal pain: a systematic review. Pain Physician 2007; 10: 185-212.

5. el-Khoury GY, Ehara S, Weinstein JN, Montgomery WJ, Kathol $M H$. Epidural steroid injection: a procedure ideally performed with fluoroscopic control. Radiology 1988; 168: 7-554.

6. Hildebrandt $J$. Relevance of nerve blocks in treating and diagnosing low back pain-is the quality decisive? (German). Schmerz 2001; 15: 474-83.

7. Manchikanti L, Bakhit CE, Pakanati RR, Fellows B. Fluoroscopy is medically necessary for the performance of epidural steroids. Anesth Analg 1999; 89: 1330-1.

8. Fredman B, Nun MB, Zohar E, et al. Epidural steroids for treating "failed back surgery syndrome": is fluoroscopy really necessary? Anesth Analg 1999; 88: 367-72.

9. Manchikanti L, Cash KA, Pampati V, McManus CD, Damron KS. Evaluation of fluoroscopically guided caudal epidural injections. Pain Physician 2004; 7: 81-92.

10. Tsui BC, Gupta S, Finucane B. Confirmation of epidural catheter placement using nerve stimulation. Can J Anaesth 1998; 45: 640-4.

11. Tsui BC, Wagner A, Cave D, Seal R. Threshold current for an insulated epidural needle in pediatric patients. Anesth Analg 2004; 99: 694-6.

12. Tsui BC, Bury J, Bouliane M, Ganapathy S. Cervical epidural analgesia via a thoracic approach using nerve-stimulation guidance in adult patients undergoing total shoulder replacement surgery. Acta Anaesthesiol Scand 2007; 51: 255-60.

13. Prusinkiewicz C, Lang $S$, Tsui BC. Lateral cervical epidural catheter placement using nerve stimulation for continuous unilateral upper extremity analgesia following a failed continuous peripheral nerve block. Acta Anaesthesiol Scand 2005; 49: 579-82.

14. American Society of Anesthesiologists Task Force on Chronic Pain Management; American Society of Regional Anesthesia and Pain Medicine. Practice guidelines for chronic pain management: an updated report by the American Society of Anesthesiologists Task Force on Chronic Pain Management and the American Society of Regional Anesthesia and Pain Medicine. Anesthesiology 2010; 112: 810-33.

15. Tsui BC, Sze CK. An in vitro comparison of the electrical conducting properties of multiport versus single-port epidural catheters for the epidural stimulation test. Anesth Analg 2005; 101: 1528-30.

16. Charghi R, Chan SY, Kardash KJ, Finlayson RJ, de Tran $Q H$. Electrical stimulation of the epidural space using a catheter with a removable stylet. Reg Anesth Pain Med 2007; 32: 152-6.

17. Tsui BC. Predicting caudal epidural analgesia using nerve stimulation. Anaesthesia 2001; 56: 816-7.

18. Tsui BC, Guenther C, Emery D, Finucane B. Determining epidural catheter location using nerve stimulation with radiological confirmation. Reg Anesth Pain Med 2000; 25: 306-9.

19. Airaksinen O, Brox JI, Cedraschi C, et al. Chapter 4. European guidelines for the management of chronic nonspecific low back pain. Eur Spine J 2006; 15(Suppl 2): S192-300.

20. Hoftman NN, Ferrante FM. Diagnosis of unintentional subdural anesthesia/analgesia: analyzing radiographically proven cases to define the clinical entity and to develop a diagnostic algorithm. Reg Anesth Pain Med 2009; 34: 12-6.

21. Stitz MY, Sommer HM. Accuracy of blind versus fluoroscopically guided caudal epidural injection. Spine (Phila Pa 1976) 1999; 24: $1371-6$. 
22. Abram SE, O'Connor TC. Complications associated with epidural steroid injections. Reg Anesth 1996; 21: 149-62.

23. Heavner JE, Bosscher H. Epiduroscopy and radiation exposure. Reg Anesth Pain Med 2009; 34: 79.

24. Zhou Y, Singh N, Abdi S, Wu J, Crawford J, Furgang FA. Fluoroscopy radiation safety for spine interventional pain procedures in university teaching hospitals. Pain Physician 2005; 8: 49-53.

25. Manchikanti L, Pampati V, Boswell MV, Smith HS, Hirsch JA. Analysis of the growth of epidural injections and costs in the Medicare population: a comparative evaluation of 1997, 2002, and 2006 data. Pain Physician 2010; 13: 199-212.

26. Hogan $Q H$, Mark L. Subdural injection: what's the gold standard? Reg Anesth Pain Med 2009; 34: 10-1.

27. Hogan $Q$. Epidural catheter tip position and distribution of injectate evaluated by computed tomography. Anesthesiology 1999; 90: 964-70.
28. Tamai H, Sawamura S, Kanamori Y, Takeda K, Chinzei M, Hanaoka $K$. Thoracic epidural catheter insertion using the caudal approach assisted with an electrical nerve stimulator in young children. Reg Anesth Pain Med 2004; 29: 92-5.

29. Ozawa T, Kaneko H, Nomura T, Asano M. Usefulness of epidural nerve stimulation to confirm epidural catheter placement (Japanese). Masui 2002; 51: 400-4.

30. Tsui BC, Seal R, Koller J, Entwistle L, Haugen R, Kearney $R$. Thoracic epidural analgesia via the caudal approach in pediatric patients undergoing fundoplication using nerve stimulation guidance. Anesth Analg 2001; 93: 1152-5.

31. Dashfield AK, Taylor MB, Cleaver JS, Farrow D. Comparison of caudal steroid epidural with targeted steroid placement during spinal endoscopy for chronic sciatica: a prospective, randomized, double-blind trial. Br J Anaesth 2005; 94: 514-9.

32. Anderson SR, Racz GB, Heavner J. Evolution of epidural lysis of adhesions. Pain Physician 2000; 3: 262-70. 